with the experimental procedure which includes 58- and 88-sec periods.

The observed and calculated responses are shown in Fig. 1 .

No attempt was made to reproduce the fluctuations in the experimental curve. These are believed purely random and are consistent with variations in the observed respenses of different cultures of Gonyaulax monilata.

We thank Dr. Giorgio Soli of the Naval Ordnance Test Station for the experimental data.

Research Department,

Gilbert J. Plain

U.S. Naval Ordnance Test Station,

China Lake, California.

Stanford University,

Karen E. Platn

Stanford, California.

\section{Conocytic Vessel Elements in Dioscorea alata L.}

During the course of a morpho-histogenic study on the cultivated species of Dioscorea of Gujarat State, India, certain observations were made on the development of the vessel elements in the stem of D. alata (Kamodio variety). The vessel elements of the plant were found to be unusual in being very broad with long scalariform plates which often exhibit a branching of the bars in the plate $e^{1,2}$.

The metaxylem vessel elements are $1 \cdot 3 \mathrm{~cm}$ long, and have perforation plates varying from oblique, elongated and scalariform to transverse, rounded and reticulate. The tracheids are branched and show scalariform pitting. Intermediate types, such as vessel elements with only one perforation plate at one of the ends and 'vessel-tracheids',
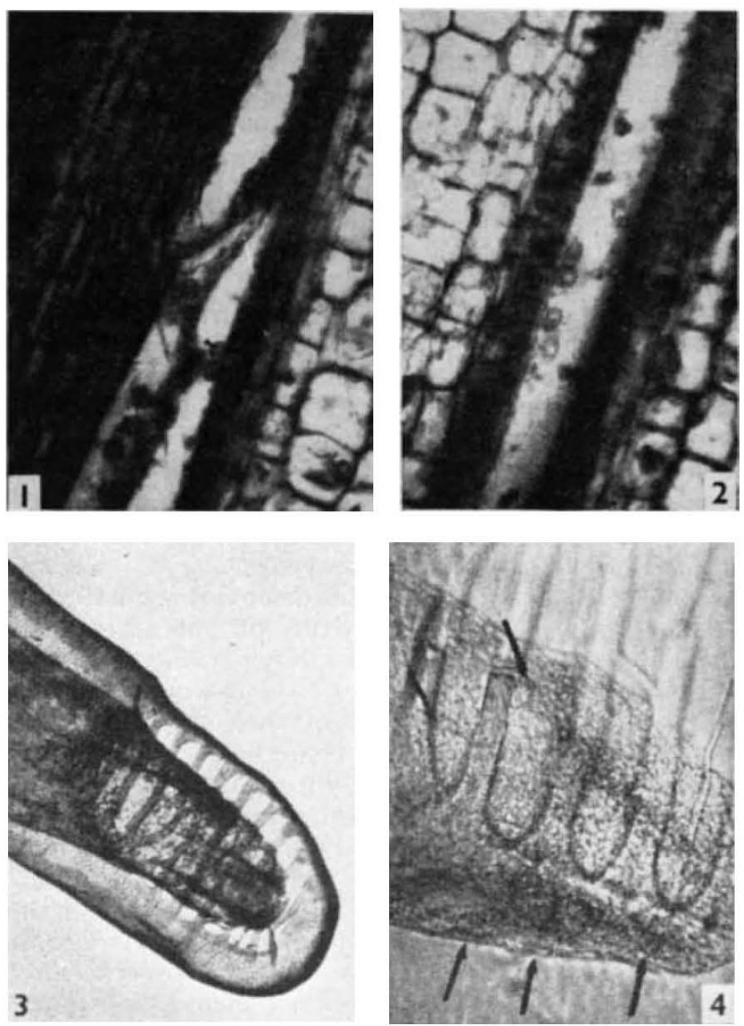

Fig. 1. Two differentiating vessel elements; note nuclei lying against end wall in upper cell $(x 250)$

Hig. 2. An elongated vessel element near apical region of the sten showing a row of four nuclei $(\times 250)$

lig. 3. Vessel element with perforation plate, showing persistent protoplast. The lower four bars were damaged because of the pressure applied to the macerated element $(x 63)$

Fig. 4. Persisting nuclei at end of the vessel element. Note the broken bars of the perforation plate $(\times 250)$ are alsu present. These latter are tracheid-like elements with a small perforation plate composed of a few branched and unbranched bars. It is doubtful if any membrane is present between them. The vessel-tracheids have small, simple, elongated pits on the other parts of the wall, and are obviously of a different eategory from those defined by Fahn ${ }^{3}$.

The protoplast of the vessel element of $D$. alata is cœnocytic. As many as 7-9 or more nuclei were observed in vessel elements, $0.5 \mathrm{~cm}$ long. The multinucleate phase in vessel differentiation is due to divisions of the nucleus of the mother cell (Figs. 1 and 2). This contradicts Hill and Freeman's observations according to which the multinucleate condition in the central vessels of the root of $D$. prehensilis is due to an obliteration of the transverse and lateral walls of the elements ${ }^{4}$. The nuclei are scattered throughout the length of the vessel elements during the phase of elongation.

Later the protoplast becomes fragmented into disconnected strands. Pirotta and Buscalioni (1898) ${ }^{5}$ and Nermec (1910) reported that in the Dioscoreaceae the perforation of the end walls occurs after the disintegration of the nuclei; but in my material the conocytic protoplast has been found to persist even after the formation of the perforation plate (Figs. 3 and 4), which is most unusual. Eames and MacDaniels ${ }^{8}$ and Esau ${ }^{7}$ now suggest that in the development of the vessel the protoplast must persist at least until the completion of the perforation plate.

I thank Prof. P. Maheshwari for helpful suggestions and the University of Gujarat for supporting this work.

Department of Botany,

J. J. SHAH

University School of Sciences, Gujarat University,

Ahmedabad.

${ }^{1}$ Cheadle, V. I., Amer. J. Bot., 29, 441 (1942).

${ }^{2}$ Cheadle, V. I., Amer. J. Bot., 30, 11 (1943).

${ }^{3}$ Fahn, A., New Phytol., 53, 530 (1954).

${ }^{4}$ Hill, T. G., and Freeman, W. G., Ann. Bot., 17, 415 (1903).

${ }^{5}$ Esau, K., and Hewitt, W. B., Hilgardia, 13, (5) 229 (1940).

${ }^{6}$ Eames, A. J., and MacDaniels, L. H., Nature, 176, 39 (1955).

7 Esau, K., Anatomy of Seed Plants, p.! 82, Fig. 8.4 (John Wiley, 1960).

\section{Reticulate Cuticle on Leaf Epidermis in Hevea brasiliensis Muell.}

VAriations of the surface patterns of cuticles have attracted the attention of both plant morphologists and physiologists. The formation and the functions of cuticle have been previously discussed ${ }^{1-3}$. Electron microscopic studies have revealed much greater details ${ }^{4,5}$. Observations under the light microscope show three main types of cuticles, namely, lamellate, striate and reticulate $^{1,8,7}$, and the effects of cell growth are mentioned as chief causes for the formation of different types ${ }^{1,4}$. Of these three, occurrence of the lamellate cuticle appears to be more common than the other two. Different genera that possess striated cuticles have been listed ${ }^{3, ?}$.

Martens ${ }^{6,8}$ examined in detail the cuticle pattern on the floral parts of Tradescantia. In most instances he observed lamellate and striate cuticles and only in few cases the reticulate type. Scarcely any other report has been made about the occurrence of reticulate cuticle in plants. The present observations illustrate the occurrence and nature of reticulate cuticle on the lower epidermis in Hevea brasiliensis.

Leaves of $H$. brasiliensis were collected from plants growing in the University compound. Peels of upper and lower epidermis of leaves were made and observed under the microscope. Some of these were stained with 1 per cent safranin. Transverse as well as paradermal sections of leaves, $5-8 \mu$ thick, were prepared and stained with safranin and green. The cells of the upper epidermis, in the surface view, are angular in outline and covered with thick lamellate cuticle. Lower opidermal cells are wavy 